\title{
Ecological and health risk assessment of organochlorine pesticides in an urbanized river network of Shanghai, China
}

\author{
Chong Chen ${ }^{1}$, Wenbing Zou ${ }^{2}$, Songsong Chen ${ }^{1}$, Kai Zhang ${ }^{1}$ and Limin Ma ${ }^{1 *}$
}

\begin{abstract}
Background: Organochlorine pesticides (OCPs) are currently still threatening the ecological environment and people's health. However, studies that investigate OCP pollution levels in an urbanized river network of an entire city with a high density of rivers, such as Shanghai, have rarely been reported. In addition, due to the pressure of high population densities, ecological risk and health hazard assessments of OCPs in river networks are a knowledge gap that needs to be urgently filled. Thus, in this study, the concentrations, distribution, and partitioning of OCPs are evaluated in an ecological and health risk assessment for the urbanized river network of Shanghai. The goal is to establish connections among OCP residues and establish their impacts on ecological and human health.

Results: The concentrations of 26 OCPs in the urbanized river network of Shanghai ranged from 43.90 to $342.74 \mathrm{ng} / \mathrm{L}$, with a mean value of $181.34 \mathrm{ng} / \mathrm{L}$. Some OCPs formed triangle-shaped areas with higher local ecological risks than other areas, and there were nine OCPs of high risk in some areas. The health risk assessment results showed that the ranking of the incremental lifetime cancer risk (ILCR) for dermal contact according to age and gender was adults $>$ children $>$ seniors $>$ adolescents, and females $>$ males, while the ranking of the ILCR caused by mistaken oral intake was adults > children > adolescents > seniors, and females $>$ males. The non-carcinogenic risk hazard index (HI) values of both exposure routes were less than one.

Conclusion: OCP concentrations in the northern and southern regions of Shanghai were significantly higher than in other regions, and the partition coefficient $\left(K_{p}\right)$ values of the $\sum_{26}$ OCPs were negatively correlated with the total suspended solids' (TSS) contents $(p<0.01)$. The ecological risks were relatively higher in agricultural areas. The ILCR for dermal contact and mistaken oral intake were generally low, except for adults, whose ILCR caused by dermal contact were at moderate risk. In addition, OCPs in river waters did not pose significant non-carcinogenic health hazards for a majority of the people.
\end{abstract}

Keywords: Organochlorine pesticides, River network, Distribution, Ecological risk, Health risk

\section{Background}

Since the 1940s, pesticides have been widely applied to protect agricultural crops, and the production and use of pesticides have been steadily increasing. China is one of

\footnotetext{
*Correspondence: 1710790@tongji.edu.cn

1 State Key Laboratory of Pollution Control and Resources Reuse, College of Environmental Science and Engineering, Tongji University, 1239 Siping Road, Shanghai 200092, People's Republic of China

Full list of author information is available at the end of the article
}

the largest producers and users of pesticides in the world [1]. Prior to 1982 , OCPs accounted for nearly $80 \%$ of China's pesticides [1]. Organochlorine pesticides (OCPs) are characterized as persistent in the environment and can bioaccumulate through the food chain. They can also be transported long distances like most organo-pesticides, as evidenced by the accumulation in arctic wildlife [2]. Due to their adverse environmental impacts, they have gradually been replaced by other types of pesticides, such as organophosphate insecticides, since the first

\section{Springer Open}

(c) The Author(s) 2020. This article is licensed under a Creative Commons Attribution 4.0 International License, which permits use, sharing, adaptation, distribution and reproduction in any medium or format, as long as you give appropriate credit to the original author(s) and the source, provide a link to the Creative Commons licence, and indicate if changes were made. The images or other third party material in this article are included in the article's Creative Commons licence, unless indicated otherwise in a credit line to the material. If material is not included in the article's Creative Commons licence and your intended use is not permitted by statutory regulation or exceeds the permitted use, you will need to obtain permission directly from the copyright holder. To view a copy of this licence, visit http://creativecommons.org/licenses/by/4.0/. 
regulation of OCPs was promulgated in 1982 [3]. However, owing to the large amount of OCPs used for such a long time in the past, their residues in the environment are still hot spots of contamination. During the past two decades, high levels of OCPs in the water, sediments, and aquatic biota of many important rivers in China, such as the Shayin River [4], the Yellow River [5], and the Pearl River [6], could be still detected. South China (the Pearl River Delta) has been considered as one of the areas in China with high environmental concentrations of pesticides [6]. Thus, OCPs are still threatening the ecological environment and people's health today.

Micropollutants in water, such as OCPs, have become one of the most urgent environmental problems in China. Rivers are one of the most important sources of drinking water, and urbanized rivers are closely related to human life in all aspects in the south of China. Traditional environmental monitoring primarily focuses on organic matter [Biochemical Oxygen Demand (BOD), Chemical Oxygen Demand (COD)], nutrient loading (nitrogen, phosphorus), certain heavy metals, and other traditional pollutants in water, and little attention is paid to organic micropollutants, such as OCPs [1]. Therefore, the risks caused by these micropollutants to aquatic biota and human health are even more worrying. Up to now, some site-specific studies have given people knowledge of the OCP contamination status for a few hot spot areas $[1,7,8]$, but most regions in China are still lacking in relevant data. In addition, the levels of exposure doses and associated risks remain largely unknown. Hence, a longterm monitoring program of river pollution by OCPs is extremely necessary.

Previous studies have established some ecological and health risk assessment criteria for OCPs in water, such as the Norwegian classification system [9], the National Recommended Water Quality Criteria of the United States Environmental Protection Agency [10], the Environmental Quality Standards for Surface Water of China (GB 3838-2002) [11], and the standards recommended by the Joint FAO/WHO Meeting on Pesticide Residues [12]. However, there may be uncertainties using criteria from different parts of the world to measure local environmental pollution. The sensitivity of species and population to pesticides in China may be different from that in other countries on which the criteria are based. The suspended particulate matter and sediment properties may give rise to different partition patterns. Temperature, precipitation, and other factors may also differ significantly, which can affect the degradation and diffusion of OCPs [1]. Moreover, the criteria set by each country are not necessarily complete. For example, China's water quality assessment criteria pay too little attention to OCPs, which may overestimate the proportion of river waters deemed safe [13]. Many OCPs that are targeted by the Stockholm Convention are prone to cause cancer and teratismus hermpahroditicus or known to damage the nervous system and endanger the growth of normal infants and children $[13,14]$. As a result, an objective and all-round assessment method is needed to evaluate the current state of OCP water pollution in China, and such an assessment can provide baseline information for further regulatory efforts.

Shanghai is located on the Yangtze River Delta at the estuary of the Yangtze River. It is located in a typical region containing an urbanized river network with farmland areas $\left(1820 \mathrm{~km}^{2}\right)$, accounting for approximately $28.71 \%$ of the total land $\left(6340 \mathrm{~km}^{2}\right)$ [15]. It is an important coastal city in China with functions of agriculture, commerce, industry, residences, and others. Currently, studies that have investigated OCP pollution in water have typically focused on rivers, lakes, and reservoirs in a few hot-spot areas [13]. However, studies that have investigated OCP pollution levels in the urbanized river network of an entire city with high-density rivers, such as Shanghai, have rarely been reported. In addition, a large population of more than 24 million in Shanghai makes it an area with the added pressure of a high population density of 3823 individuals per $\mathrm{km}^{2}$ [15]. The ecological risk and health hazard assessment of OCPs in the river network is currently a knowledge gap that needs to be urgently filled. Therefore, the purposes of this study are to understand the composition characteristics of OCPs in Shanghai's river waters and to analyze the spatial distribution and partitioning of OCPs among different intensive land-use types. The ultimate aim is to establish an appropriate method based on the characteristics of Chinese populations and species to assess the ecological and health risks caused by OCPs in river waters. This study can provide a scientific basis for the evaluation and control of OCP pollution worldwide.

\section{Materials and methods Study area and sampling collection}

Shanghai is one of the largest international metropolises in China and is a center of business, habitancy, farming, industry, and other activities. It covers an area of approximately $6340.5 \mathrm{~km}^{2}$ and is situated on the alluvial plain of the Yangtze River Delta with an average altitude of $4 \mathrm{~m}$ above sea level [16]. There are approximately 33,127 rivers and streams in Shanghai, with a total length and a total water surface area of approximately $24,915 \mathrm{~km}$ and $642.7 \mathrm{~km}^{2}$, respectively [17]. These rivers are interconnected, thus forming an urbanized river network. The implementation of the coastal development strategy in 1984 has had brought serious influences on the quality 
of the river network in Shanghai, and has even destroyed the original ecological balance [18].

River water samples from 53 sampling sites in the urbanized river network were collected from December 2018 to February 2019. The sampling sites were distributed equably across the entire city of Shanghai, spanning from $30^{\circ} 40^{\prime} \mathrm{N}$ to $31^{\circ} 53^{\prime} \mathrm{N}$ and from $120^{\circ} 52^{\prime} \mathrm{E}$ to $122^{\circ}$ $12^{\prime} \mathrm{E}$, with 10 sites located in suburban towns, 6 sites in island areas, 11 sites in industrial areas, 15 sites in agricultural areas, and 11 sites in the inner city (Fig. 1). Additional file 1: Table S1 describes the detailed information on the sampling sites of diverse intensive land-use types. At each site, triplicates of river water samples were collected at depths of 5-15 cm from the middle of the river using a plexiglass sampler, stored in 1-L brown glass bottles, and immediately transported to a laboratory at $4{ }^{\circ} \mathrm{C}$ with preservatives $(0.10 \mathrm{~g} / \mathrm{L}$ ascorbic acid, $0.35 \mathrm{~g} / \mathrm{L}$ ethylenediaminetetraacetic acid disodium salt, and $9.4 \mathrm{~g} / \mathrm{L}$ potassium dihydrogen citrate). Then, the samples were analyzed within $24 \mathrm{~h}$. In addition, the sampling sites were located using a global positioning system (GPS) device.

\section{Analysis of OCPs and total suspended solids (TSS) Pretreatment of surface water samples}

A 1-L river water sample was directly filtered using 0.45$\mu \mathrm{m}$ glass microfiber filters (GFF, ANPEL, China) that were baked in a muffle furnace at $400{ }^{\circ} \mathrm{C}$ for $4 \mathrm{~h}$. OCPs in filtrate were extracted using solid phase extraction (SPE,
ANPEL CG1824, China) with 6-mL cartridges filled with $500 \mathrm{mg}$ C18 (ANPEL, China), and the SPE procedure was performed according to the method recommended by the United States Environmental Protection Agency (USEPA) [19]. First, the SPE column was activated into balance using $5 \mathrm{~mL}$ ethyl acetate, $10 \mathrm{~mL}$ methanol, and $10 \mathrm{~mL}$ ultra-pure water successively. Then, the loading water velocity was controlled at $10 \mathrm{~mL} / \mathrm{min}$. In the next step, which aimed to target the OCPs, the sample was eluted with $5 \mathrm{~mL}$ methanol and $5 \mathrm{~mL}$ dichloromethane (DCM) after extraction. The OCP eluent was dried using anhydrous sodium sulfate, which was also calcined for $4 \mathrm{~h}$ at $400{ }^{\circ} \mathrm{C}$ and then transferred with DCM and reduced to $\sim 0.7 \mathrm{~mL}$ using an antiseptic 24-bit nitrogen blower (ANPEL DC24-Rt, China). Finally, the concentrated sample was fixed to $1 \mathrm{~mL}$ after adding $\sim 0.3 \mathrm{~mL}$ methanol.

\section{Pretreatment of the suspended particulate matter (SPM)}

The suspended particulate matter (SPM) separated using GFF was filtered from $1 \mathrm{~L}$ of river water sample and allowed to dry naturally. After drying, the total suspended solid (TSS) content of the river water could be calculated according to the added weight of the GFF. The procedure for OCP extraction in the SPM was modified from the procedure used by Liu et al. In brief, the SPM in each sample was extracted using $10 \mathrm{~mL}$ methanol and $10 \mathrm{~mL}$ DCM in turn for $48 \mathrm{~h}$. After filtered with a nylon syringe filter (ANPEL, China), the extractions were then

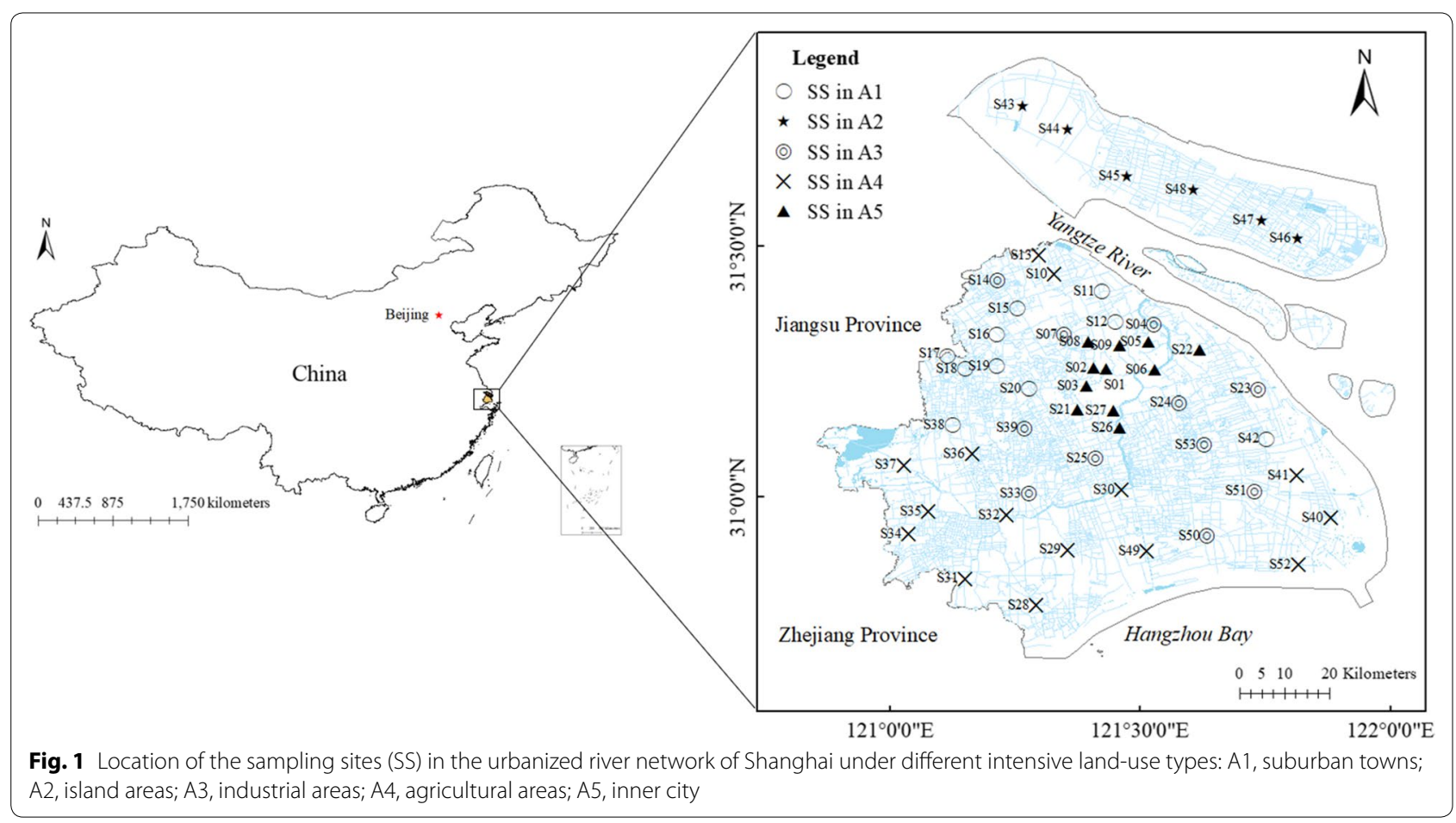


reduced to $\sim 0.7 \mathrm{~mL}$ using the antiseptic 24-bit nitrogen blower (ANPEL DC24-Rt, China). The concentrated sample was then purified using a self-packet anhydrous sodium sulfate column $\left(2 \mathrm{~g}\right.$, baked for $4 \mathrm{~h}$ at $400{ }^{\circ} \mathrm{C}$, and washed using DCM and $n$-hexane of twofold column volumes). After that, the sample was fixed to $1 \mathrm{~mL}$ using $\sim 0.3 \mathrm{~mL}$ methanol for the gas chromatographymass spectrophotometry (GC-MS) analysis.

\section{$O C P$ quantification and quality control}

GC-MS (Thermo Fisher Trace DSQ II-MS, USA) in EI mode was used for the OCP quantification. The capillary column used was HP-5MS $(30.0 \mathrm{~m} \times 0.25 \mathrm{~mm} \times 0.25 \mu \mathrm{m})$. The carrier gas was helium at a flow rate of $1.2 \mathrm{~mL} /$ min under the constant flow mode. The injector was set at $275{ }^{\circ} \mathrm{C}$. The oven temperature was programmed as follows: initially at $70{ }^{\circ} \mathrm{C}$ (equilibrium time $1.5 \mathrm{~min}$ ), increased to $200{ }^{\circ} \mathrm{C}$ at the rate of $10{ }^{\circ} \mathrm{C} / \mathrm{min}$, continually increased before reaching at $320{ }^{\circ} \mathrm{C}$ at the rate of $7{ }^{\circ} \mathrm{C} /$ $\mathrm{min}$, and then held for $3 \mathrm{~min}$.

The internal standard method recommended by the USEPA (2012) was adopted in this study to quantify the concentrations of OCPs. The internal standards are pure compounds that are isotopically labeled analogs of selected method analytes that are added to each sample prior to extraction in a known amount in order to measure the relative responses of the OCPs, and also determine the recoveries in the real samples [19]. Deuterated polycyclic aromatic hydrocarbons (PAHs) of $100 \mathrm{ng} / \mu \mathrm{L}$ ( $\mathrm{d}_{10}$-acenaphthene, $\mathrm{d}_{10}$-phenanththrene, $\mathrm{d}_{12}$-chrysene) were used as the internal standard solution (Sigma, USA) in this study [19].

The linear correlation coefficients $\left(R^{2}\right)$ of the standard calibration curves for target OCPs ranged from 0.9906 to 0.9993 , with a relatively high repeatability. Procedural blanks and field blanks were analyzed routinely to monitor the procedural performance and interference. One blank and one standard were conducted every ten samples. The limits of detection (LOD) of all the OCPs ranged between 0.24 and $1.83 \mathrm{ng} / \mathrm{L}$ with a signal-to-noise ratio $(\mathrm{S} / \mathrm{N})$ of three. In addition, the limits of quantification (LOQ) ranged from 0.80 to $6.14 \mathrm{ng} / \mathrm{L}$, with an $\mathrm{S} / \mathrm{N}$ of 10. All the method analyses were under the LOD in the blank samples. The recoveries from this method were $62.5 \%-126.3 \%$ during the surface water phase and $60.8 \%-114.8 \%$ during the SPM phase. Values for OCPs lower than the LOQ were reported as half of the LOQ, while values lower than the LOD were substituted with zero prior to the statistical analysis.

The standard OCPs included etridiazole, chloroneb, propachlor, $\alpha-\mathrm{HCH}, \beta-\mathrm{HCH}, \gamma-\mathrm{HCH}, \delta-\mathrm{HCH}, \mathrm{HCB}$, chlorothalonil, heptachlor, aldrin, dacthal (DCPA), heptachlor epoxide, trans-chlordane, cis-chlordane, endosufan I, endosufan II, trans-nonachlor, 4,4'-DDE, 4,4'-DDD, 4,4'-DDT, dieldrin, endrin, chlorobenzilate, endosufan sulfate, and methoxychlor, and the internal standards were purchased from Sigma. All of the solvents (e.g., ethyl acetate, methanol, and DCM) used for the sample processing and analysis were high-performance liquid chromatography (HPLC) grade and obtained from ANPEL.

\section{Statistical analysis}

The partition coefficient of the OCPs between the SPM and surface water $\left(K_{p}, \mathrm{~L} / \mathrm{g}\right)$ was calculated as follows [18]:

$$
K_{p}=C_{p} / C_{d}
$$

where $C_{p}$ is the OCPs concentration in the SPM, ng/g; and $C_{d}$ the OCPs concentration in the surface water, $\mathrm{ng} / \mathrm{L}$.

ArcGIS version 10.2 (ESRI, USA) was used for the spatial distribution analysis of the 26 OCP concentrations and their ecological risks. The graphs were drawn using the interpolation method, and the inverse distance weight (IDW) method was adopted in the interpolation model.

\section{Ecological risk assessment}

The ecological risk of OCPs to aquatic organisms was assessed using the risk quotient (RQ) method, which was performed by the calculation of the RQ for the detected OCPs [20].

$$
\mathrm{RQ}=\mathrm{EEC} / \mathrm{PNEC}
$$

where RQ is the risk quotient; EEC the measured concentration of each OCP, $\mathrm{mg} / \mathrm{L}$; and PNEC the predicted no-effect concentration for a particular OCP, $\mathrm{mg} / \mathrm{L}$.

The PNEC was calculated as follows [20]:

$$
\mathrm{PNEC}=\mathrm{HC}_{5} / \mathrm{AF}
$$

where $\mathrm{HC}_{5}$ is the $\mathrm{OCP}$ concentration at which $5 \%$ of species are exposed to chronic hazards, $\mathrm{mg} / \mathrm{L}$; and $\mathrm{AF}$ an assessment factor, which considers the uncertainty between laboratory toxicology tests and the real environment. In this study, $\mathrm{AF}=100$ [4].

$\mathrm{HC}_{5}$ was calculated using species sensitivity distribution (SSD) method [21]. The acute toxicity data, such as the median lethal concentration $\left(\mathrm{LC}_{50}\right)$ or median effective concentration $\left(\mathrm{EC}_{50}\right)$ of fish (freshwater), daphnia (freshwater), green alga (freshwater), earthworm (freshwater), fish (seawater), and shrimp (seawater) for 26 OCPs, were obtained from ECOSAR version 2.0 (USEPA, USA) as far as possible (Additional file 1: Table S2). Due to the scarcity of chronic toxicity data, no observed effect concentration (NOEC) or lowest observed effect 
concentration (LOEC) of fish (freshwater), daphnia (freshwater), and green alga (freshwater) for 26 OCPs were obtained using ECOSAR version 2.0 (USEPA, USA) (Additional file 1: Table S3). The acute toxicity data of each species for the same OCP monomer were arranged in order from small to large, and the corresponding cumulative probability $(P)$ was calculated as follows:

$$
P=n /(N+1)
$$

where $n$ is the ordinal number. The minimum ordinal number was set to 1 , and the maximum ordinal number was set to $N$.

The logarithmic value of the OCP's acute toxicity data for each species was used as the abscissa, and the corresponding cumulative probability was used as the ordinate. Seven types of SSD curve models were selected in this study, namely the Boltzmann, Logistic, Gaussian, Lorentzian, Exponential, Logarithm, and Log-normal models. Origin version 8.0 (OriginLab, USA) was used for drawing and model fitting. The model suitable for deducing the OCP concentration at which $5 \%$ of species are exposed to acute hazards $\left(A H C_{5}\right)$ was determined according to goodness of fit, and the $A H C_{5}$ values were obtained (Additional file 1: Table S4).

The ratios between the acute toxicity data $\left(\mathrm{EC}_{50}\right.$ or $\mathrm{LC}_{50}$ ) and the chronic toxicity data (NOEC or LOEC) of fish (freshwater), daphnia (freshwater), and green alga (freshwater) were determined, and then the geometric average value $(F A C R)$ of the three ratios was obtained. Therefore, the $H C_{5}$ was eventually calculated as follows [21] (Additional file 1: Table S4):

$$
\mathrm{HC}_{5}=\mathrm{AHC}_{5} / \mathrm{FACR} \text {. }
$$

According to different evaluation criteria and management purposes, the classification of ecological risks was different $[4,6,22,23]$. Overall, an $R Q$ value greater than 1 indicates that the concentrations of OCPs in the environment are higher than the predicted no-effect concentrations. Subsequently, in the prior literature, ecological risks could be divided into five levels based on the RQ value: very low risk $(R Q<0.01)$, low risk $(0.01 \leq R Q<0.1)$, moderate risk $(0.1 \leq \mathrm{RQ}<1)$, high risk $(1 \leq \mathrm{RQ}<10)$, and very high risk $(\mathrm{RQ} \geq 10)[23]$.

\section{Health risk assessment}

The river network of Shanghai is primarily used for landscape water, and in this exposure scenario, the health risks of OCPs from respiratory intake are nearly negligible $[4,24]$. Therefore, in this study, the carcinogenic and non-carcinogenic risks of OCPs from dermal contact and mistaken oral intake were focused on [25]. The citizens of Shanghai were divided into eight population groups according to age and gender: children (4-10 years), adolescents (11-17 years), adults (18-60 years), and seniors (61-70 years) for both males and females [26]. The exposure dose for each population group caused by dermal contact was calculated as follows [27]:

$$
\mathrm{EED}=C_{w} \times \mathrm{SA} \times \mathrm{PC} \times \mathrm{ET} \times \mathrm{EF} \times \mathrm{CF} \times \mathrm{ED} /(\mathrm{BW} \times \mathrm{AT})
$$

where EED is the estimated exposure dose per unit body weight per day of OCPs, $\mathrm{mg} /\left(\mathrm{kg}\right.$.day); $C_{w}$ the concentration of OCPs in river waters, $\mathrm{mg} / \mathrm{L}$; SA the skin contact area, $\mathrm{cm}^{2} ; P C$ the dermal permeation constant of each $\mathrm{OCP}, \mathrm{cm} / \mathrm{h} ; E T$ the daily exposure time, h/day (Additional file 1: Table S5); EF the annual exposure frequency, $\mathrm{d} / \mathrm{a}$ (Additional file 1: Table S5); CF the conversion factor, $\left(0.001 \mathrm{~L} / \mathrm{cm}^{3}\right)$; ED the exposure duration, a (Additional file 1: Table S6); BW the body weight, $\mathrm{kg}$ (Additional file 1: Table S6); and AT the average contact time, days (Additional file 1: Table S5).

The skin contact area $(S A)$ was calculated as follows [27]:

$$
\mathrm{SA}=239 \times H^{0.417} \times \mathrm{BW}^{0.517} \times \mathrm{SER}
$$

where $H$ is the body height, $\mathrm{cm}$ (Additional file 1: Table S6); and SER the skin exposure ratio (Additional file 1: Table S6).

The dermal permeation constant of each OCP $(P C)$ was calculated as follows [28]:

$$
\mathrm{PC}=10^{\left(-0.280+0.66 \log K_{o w}-0.0056 \mathrm{MW}\right)}
$$

where $K_{\mathrm{ow}}$ is the octanol-water partition coefficient of each OCP (Additional file 1: Table S7); and $M W$ the molecular weight of each OCP (Additional file 1: Table S7).

The exposure dose for each population group through mistaken oral intake was calculated as follows [27]:

$$
\mathrm{EED}=\mathrm{Cw} \times \mathrm{IR} \times \mathrm{EF} \times \mathrm{ED} /(\mathrm{BW} \times \mathrm{AT})
$$

where IR is the oral intake rate, L/day (Additional file 1 : Table S6).

The incremental lifetime cancer risk of population groups caused by a single OCP through a single exposure pathway in the river waters of Shanghai was calculated based on Eq. 10 [27].

$$
\mathrm{ILCR}_{\mathrm{i}}=\mathrm{EED}_{\mathrm{i}} \times \mathrm{SF}_{\mathrm{i}}
$$

where $\mathrm{ILCR}_{i}$ is the incremental lifetime cancer risk caused by the $i$ th OCP; $\mathrm{EED}_{i}$ is the estimated exposure dose per unit body weight per day of the $i$ th OCP, mg/ (kg.day); and $\mathrm{SF}_{i}$ is the cancer slope factor for the specific exposure pathway of the $i$ th $\mathrm{OCP}, \mathrm{kg} \cdot \mathrm{day} / \mathrm{mg}$ (Additional file 1: Table S7). 
The incremental lifetime cancer risk of population groups caused by 26 OCPs through dermal contact or mistaken oral intake from the river waters of Shanghai was calculated based on Eq. 11 [27].

$$
\mathrm{ILCR}=\sum_{i}^{n} \mathrm{ILCR}_{i}
$$

where ILCR is the total incremental lifetime cancer risk caused by 26 OCPs.

The loss of life expectancy was calculated using Eq. 12 [29].

$$
\mathrm{LLE}=62 \times \mathrm{ILCR} / 10^{-5}
$$

where LLE is the total loss of life expectancy caused by 26 OCPs, min.

The non-carcinogenic risk of population groups caused by a single OCP through a single exposure pathway from the river waters of Shanghai was calculated according to Eq. 13 [27].

$$
\mathrm{HI}_{i}=\mathrm{EED}_{i} / \mathrm{RfD}_{i}
$$

where $\mathrm{HI}_{i}$ is the non-carcinogenic risk hazard index caused by the $i$ th OCP; and $R f D_{i}$ is the non-carcinogenic reference dose for the specific exposure pathway of the $i$ th OCP, $\mathrm{mg} /(\mathrm{kg}$.day) (Additional file 1: Table S7).

The non-carcinogenic risk of population groups caused by 26 OCPs through dermal contact or mistaken oral intake from the river waters of Shanghai was calculated according to Eq. 14 [27].

$$
\mathrm{HI}=\sum_{i}^{n} \mathrm{HI}_{i}
$$

where $\mathrm{HI}$ is the total non-carcinogenic risk hazard index caused by 26 OCPs.

Due to the possible uncertainties in the body weights and heights at different age stages and sexes and with different probabilities of OCP concentrations in river waters, the probabilistic evaluation of health risks was conducted using a Monte Carlo simulation with 5000 runs [26]. Random body weights, body heights, and concentrations of OCPs were generated for each run based on the normal, normal, and lognormal distributions, respectively. The mean and standard deviation (SD) for generating the random body weights and heights that aligned the corresponding distribution for each age stage and each sex were obtained from the China Health Statistics Yearbook (Additional file 1: Table S6) [30]. In addition, the mean and SD for generating the random OCP concentrations for each intensive land-use type were calculated from the 53 sampling sites (Additional file 1: Table S8). The probabilistic estimation approximates the probabilistic health risks from OCPs in the river network of Shanghai [31].

Studies have shown that when the incremental lifetime cancer risk (ILCR) is higher than $1.0 \times 10^{-6}$, the carcinogenic risk cannot be ignored, and an ILCR above $1.0 \times 10^{-5}$ indicates a "not negligible" risk [32]. The USEPA regards an ILCR in the range of $1.0 \times 10^{-7}$ to $1.0 \times 10^{-4}$ as an acceptable carcinogenic risk value [33]. Some other studies have classified the ILCR into five levels: values smaller than $1.0 \times 10^{-6}$ indicate very low risk; values between $1.0 \times 10^{-6}$ and $1.0 \times 10^{-4}$ indicate low risk; values ranging from $1.0 \times 10^{-4}$ to $1.0 \times 10^{-3}$ indicate moderate risk; values between $1.0 \times 10^{-3}$ and $1.0 \times 10^{-1}$ represent high risk; and values greater than $1.0 \times 10^{-1}$ represent very high risk [24]. In this study, a five-level evaluation method was adopted to evaluate the carcinogenic risk of OCPs in the river waters of Shanghai. In addition, if the hazard index (HI) is less than 1, the noncarcinogenic risk could be considered negligible to local residents, which can be used as a criterion for a non-carcinogenic risk assessment [27].

\section{Results and discussion}

\section{Spatial distribution and partitioning of OCPs}

The concentrations of OCPs in the urbanized river network of Shanghai ranged from 43.90 to $342.74 \mathrm{ng} / \mathrm{L}$, with a mean value of $181.34 \mathrm{ng} / \mathrm{L}$ (Additional file 1: Table S8). The concentrations of OCPs ranged from $5.90 \mathrm{ng} / \mathrm{L}$ to $158.16 \mathrm{ng} / \mathrm{L}$, with an average value of $78.11 \mathrm{ng} / \mathrm{L}$ in the surface water, and from 38.00 to $191.29 \mathrm{ng} / \mathrm{L}$, with an average value of $103.22 \mathrm{ng} / \mathrm{L}$ in the SPM (Additional file 1: Table S8). The results were similar with the concentrations of 11.4-368.7 ng/L reported for the Lake Volvi, Greece [34], and slightly higher than some other waters such as $22.29-274.28 \mathrm{ng} / \mathrm{L}$ in the surface water of Aba Prefecture in China [35], 2-245 ng/L in the River Brahmaputra in India [36], and 52-285 ng/L in the Indus River of Pakistan [37] (Additional file 1: Table S9). What's more, the river waters in Shanghai were seriously contaminated by OCPs compared with the drinking water sources in south China (12.9-43.0 ng/L) [38], the underground rivers in Chongqing, China (0.76-77.67 ng/L) [39], and the Ebro River in Spain (0.05-77.6 ng/L) [40] (Additional file 1: Table S9). However, in the surface water of Konya Closed Basin of Turkey, Atoya River Basin of Nicaragua, and the Gomti River of India, the OCP levels were with higher concentrations of 190-647 ng/L, 50.0-464.6 ng/L, and 2.16-567.49 ng/L, respectively [41-43] (Additional file 1: Table S9). Furthermore, it was even more severely polluted by OCPs in the Selangor River of Malaysia and the Tonghui River of Beijing, China, whose concentrations reached $2298.9 \mathrm{ng} / \mathrm{L}$ and $3788 \mathrm{ng} / \mathrm{L}$, respectively [44, 45] (Additional file 1: Table S9). In general, the 
concentrations of OCPs in the urbanized river network of Shanghai were at a medium level compared with other areas in China and worldwide countries.

Residues of 26 OCP individuals were detected (Additional file 1: Table S8). The average concentrations of chloroneb, chlorobenzilate, and chlorothalonil were $22.71 \mathrm{ng} / \mathrm{L}, 15.92 \mathrm{ng} / \mathrm{L}$, and $11.58 \mathrm{ng} / \mathrm{L}$, respectively, which were the highest among the 26 OCPs (Additional file 1: Table S8). The average concentrations of the other 23 OCPs were from $2.08 \mathrm{ng} / \mathrm{L}$ to $9.63 \mathrm{ng} / \mathrm{L}$ (Additional file 1: Table S8). Chloroneb, propachlor, heptachlor, and heptachlor epoxide were detected at all the sampling sites (Table S8). Due to their high concentrations and high detection frequencies, these six OCPs in Shanghai's urbanized river network require more attention. According to the Environmental Quality Standards for Surface Water of China (GB 3838-2002) [11] and the National Recommended Water Quality Criteria of the United States Environmental Protection Agency [10], the OCP residues in Shanghai's river waters were far below the standard limits, indicating that in terms of OCPs, the river waters in Shanghai were relatively safe (Additional file 1: Table S8).

Figure 2 shows the spatial variations of the $\sum_{26}$ OCPs in the surface water and in the SPM of Shanghai's river waters. On the whole, the concentrations of OCPs in the northern and southern regions of Shanghai were significantly higher than that in other regions (Fig. 2), and OCP concentrations in the SPM were higher than that in the surface water, which were concentrated in $75.00-150.00 \mathrm{ng} / \mathrm{L}$ in the SPM, and 25.00-100.00 ng/L in the surface water (Fig. 2). The highest levels of OCPs were found in south of Shanghai (S49, agricultural area), reaching $342.74 \mathrm{ng} / \mathrm{L}(158.16 \mathrm{ng} / \mathrm{L}$ in the surface water and $184.58 \mathrm{ng} / \mathrm{L}$ in the SPM). In addition, the northern locations of S10 (agricultural area) and S9 (inner city) also had high levels of OCPs, concentrations of which reached $294.91 \mathrm{ng} / \mathrm{L}$ (143.81 $\mathrm{ng} / \mathrm{L}$ in the surface water and $151.10 \mathrm{ng} / \mathrm{L}$ in the SPM) and $342.28 \mathrm{ng} / \mathrm{L}(150.99 \mathrm{ng} / \mathrm{L}$ in the surface water and $191.29 \mathrm{ng} / \mathrm{L}$ in the SPM). The highconcentration regions for OCPs were also the areas with high densities of agricultural cultivation. To ensure high crop yields, farmers always used high amounts of fertilizers and pesticides, which led to high OCP residues in rivers via surface runoff [46]. In contrast, locations with low levels of OCPs consisted of the S2 and S27 sampling sites located in the inner city and S38 located in a suburban town of western Shanghai. The concentrations were $43.90 \mathrm{ng} / \mathrm{L}$ (5.89 $\mathrm{ng} / \mathrm{L}$ in the surface water and $38.00 \mathrm{ng} / \mathrm{L}$ in the SPM), $63.47 \mathrm{ng} / \mathrm{L}(12.47 \mathrm{ng} / \mathrm{L}$ in the surface water and $51.00 \mathrm{ng} / \mathrm{L}$ in the SPM), and $73.16 \mathrm{ng} / \mathrm{L}(16.45 \mathrm{ng} / \mathrm{L}$ in the surface water and $57.17 \mathrm{ng} / \mathrm{L}$ in the SPM). There

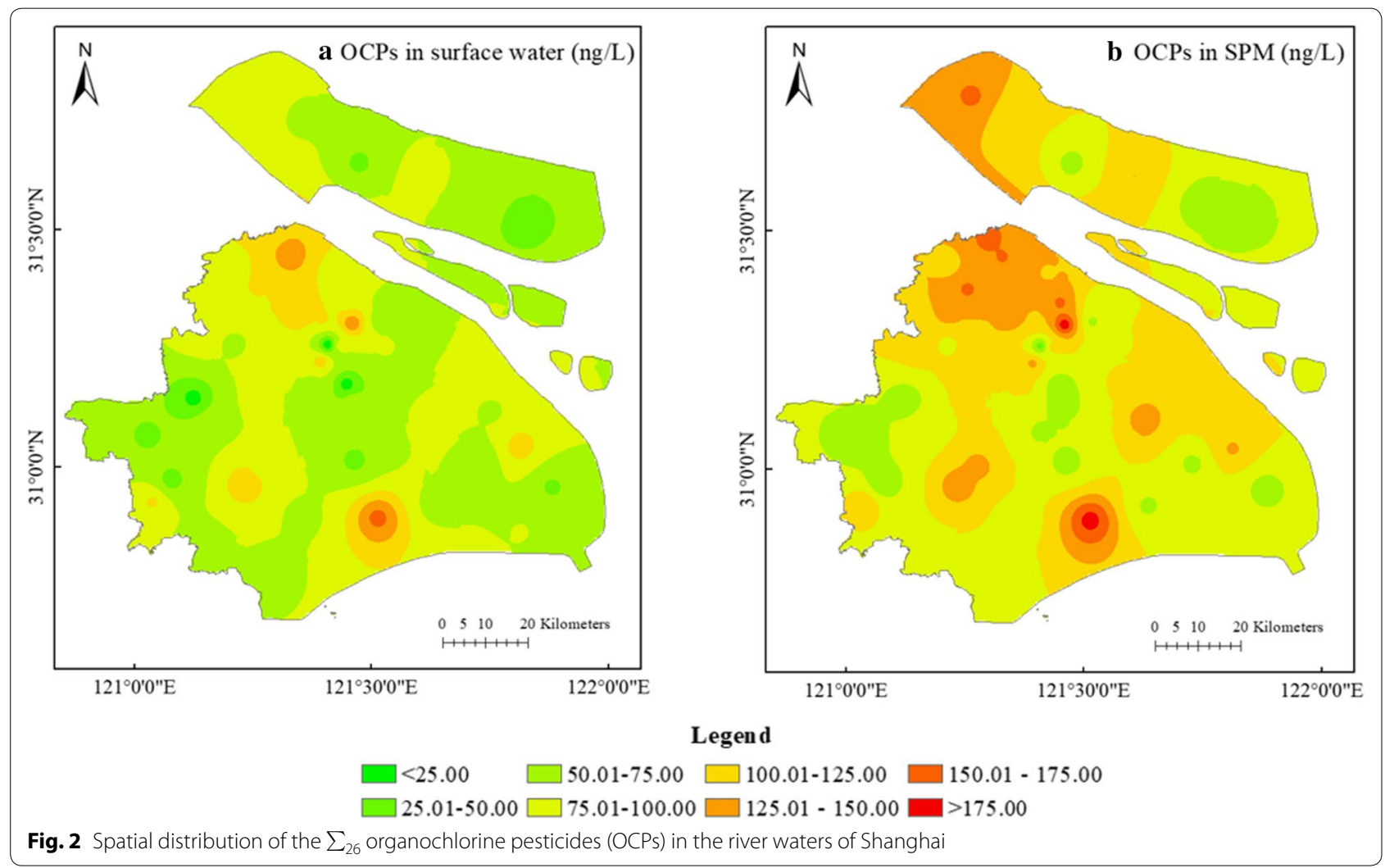


was little agricultural cultivation in these areas, and they had good hydrodynamic conditions and fast flow rates, which are conducive to the diffusion and dilution of OCPs [47].

From Additional file 1: Figure S1, it can be seen that the fluctuation in the OCP concentrations among the diverse intensive land-use types was not significant $(p>0.05)$. On average, the OCP concentrations in the river waters of suburban towns, agricultural areas, and industrial areas were relatively high, while that in the inner city and island areas were relatively low (Additional file 1: Fig. S1). The characteristics of urbanized river networks make the waters interconnected, and to some extent weaken the discrepancy of OCP levels among different intensive land-use types. It is worthy to note that the OCP concentrations in the river waters of the inner city varied most significant, and the SD reached $83.28 \mathrm{ng} / \mathrm{L}(41.53 \mathrm{ng} / \mathrm{L}$ in the surface water and $42.74 \mathrm{ng} / \mathrm{L}$ in the SPM), which may be related to frequent human activities (Additional file 1: Fig. S1). Some rivers have taken protective measures, such as the establishment of artificial ecological floating islands, sediment dredging, and regular aeration, which are beneficial for the degradation of OCPs and improvements in water quality [48-50]. However, there were also some other rivers where coastal agricultural cultivation was widespread, and the application of OCPs in the past would inevitably result in abnormally high residuals in the soils and sediments. These may be slowly released into rivers on a daily basis [51]. Therefore, it is necessary to strictly monitor urban rivers.

The $K_{\mathrm{p}}$ can be used to explain the difference in OCP concentrations between the surface water and the SPM in Shanghai's river waters. The average $K_{\mathrm{p}}$ values of $26 \mathrm{OCP}$ individuals ranged from 16.64 to $226.52 \mathrm{~L} / \mathrm{g}$, while the $K_{\mathrm{p}}$ values of the $\sum_{26}$ OCPs ranged from 1.79 to $231.87 \mathrm{~L} / \mathrm{g}$, with an average value of $50.91 \mathrm{~L} / \mathrm{g}$ (Additional file 1: Fig. S2). The OCPs with relatively high $K_{\mathrm{p}}$ values in Shanghai's river waters were trans-nonachlor, dacthal, endosufan, DDTs, aldrin, and propachlor (Additional file 1: Fig. S2). These OCPs were more easily absorbed by the SPM compared with the others. It is worth noting that the $K_{\mathrm{p}}$ values of different OCP individuals varied widely in the river waters with the SD ranging from $41.38 \mathrm{~L} / \mathrm{g}$ to $257.94 \mathrm{~L} / \mathrm{g}$, and this is because under certain conditions, such as rainfall, ebb and flow, shipping and other events, the waters can be disturbed with different degrees (Additional file 1: Fig. S2). The OCPs adsorbed on particulate matter would migrate with the water flow, affecting their in situ partition, and thus increasing the partition differences in rivers [52]. The $K_{\mathrm{p}}$ values of the $\sum_{26}$ OCPs between the surface water and the SPM were negatively correlated with the TSS contents $(p<0.01)$, which was consistent with the conclusion of Luo et al. [53] (Additional file 1:
Fig. S3). When a large amount of TSS are transferred into rivers through surface runoff, this would lead to the input of a large amount of DOC, which is a kind of adsorbate with strong adsorption capacity. This would result in the decomposition of particulate OCPs [17]. In addition, studies have shown that there was a negative correlation between clay contents and TSS [17]. When the TSS are low, fine soot-like particles can bind more OCPs, leading to high $K_{\mathrm{p}}$ values [53]. Due to the generally low levels of TSS in Shanghai's rivers $(<100 \mathrm{mg} / \mathrm{L})$ and the low solubility of OCPs in the water, the OCP concentrations in the SPM were higher than that in the surface water in most regions of Shanghai (Fig. 2).

\section{Ecological risk assessment}

The results of the predicted no-effect concentration (PNEC) values and the ecological risk assessment of OCPs in the river waters of Shanghai are shown in Additional file 1: Table S10. The PNEC values of seven OCPs were the lowest, namely, HCB, heptachlor, aldrin, trans-chlordane, cis-chlordane, trans-nonachlor, and 4,4'-DDE, ranging from 1.74 to $9.57 \mathrm{ng} / \mathrm{L}$. This indicated that they are the most toxic to aquatic organisms (Additional file 1: Table S10). The seven OCPs in Shanghai's river waters were primarily concentrated in the moderate risk group $(66.04 \%-84.91 \%)$, with the exception of aldrin, which was high risk (88.68\%) (Additional file 1: Table S10). Dieldrin, endrin, 4,4'-DDD, 4,4'-DDT, and methoxychlor were five OCPs with PNEC values ranging from 10.17 to $21.37 \mathrm{ng} / \mathrm{L}$ (Additional file 1: Table S10). OCPs in this PNEC range are also prone to toxic effects on aquatic organisms. In Shanghai's river waters, these five OCPs to aquatic organisms were primarily of moderate risk (73.58\%-84.91\%) (Additional file 1: Table S10). The remaining 14 OCPs' PNEC values, i.e., etridiazole, chloroneb, propachlor, $\alpha-\mathrm{HCH}, \beta-\mathrm{HCH}$, $\gamma-\mathrm{HCH}$ (Lindane), $\delta-\mathrm{HCH}$, chlorothalonil, DCPA, heptachlor epoxide, endofan I, chlorobenzilate, endosufan II, and endosufan sulfate, were concentrated in the range of 106.79-10,464.44 ng/L (Additional file 1: Table S10). Their PNEC values were relatively high, and thus their impacts on aquatic organisms are relatively small. Etridiazole and heptachlor epoxide were primarily in the low-risk category, accounting for $88.68 \%$ and $73.58 \%$ of the river waters in Shanghai, respectively (Additional file 1: Table S10). The other 12 OCPs were very low risk $(69.81 \%-100 \%)$ and would not cause toxicity to aquatic organisms under normal circumstances (Additional file 1: Table S10).

In terms of spatial distribution, the spatial variation of OCP individual ecological risk was not significant, which may be also related to the urbanized river network of Shanghai (Fig. 3). In the southern and northern 


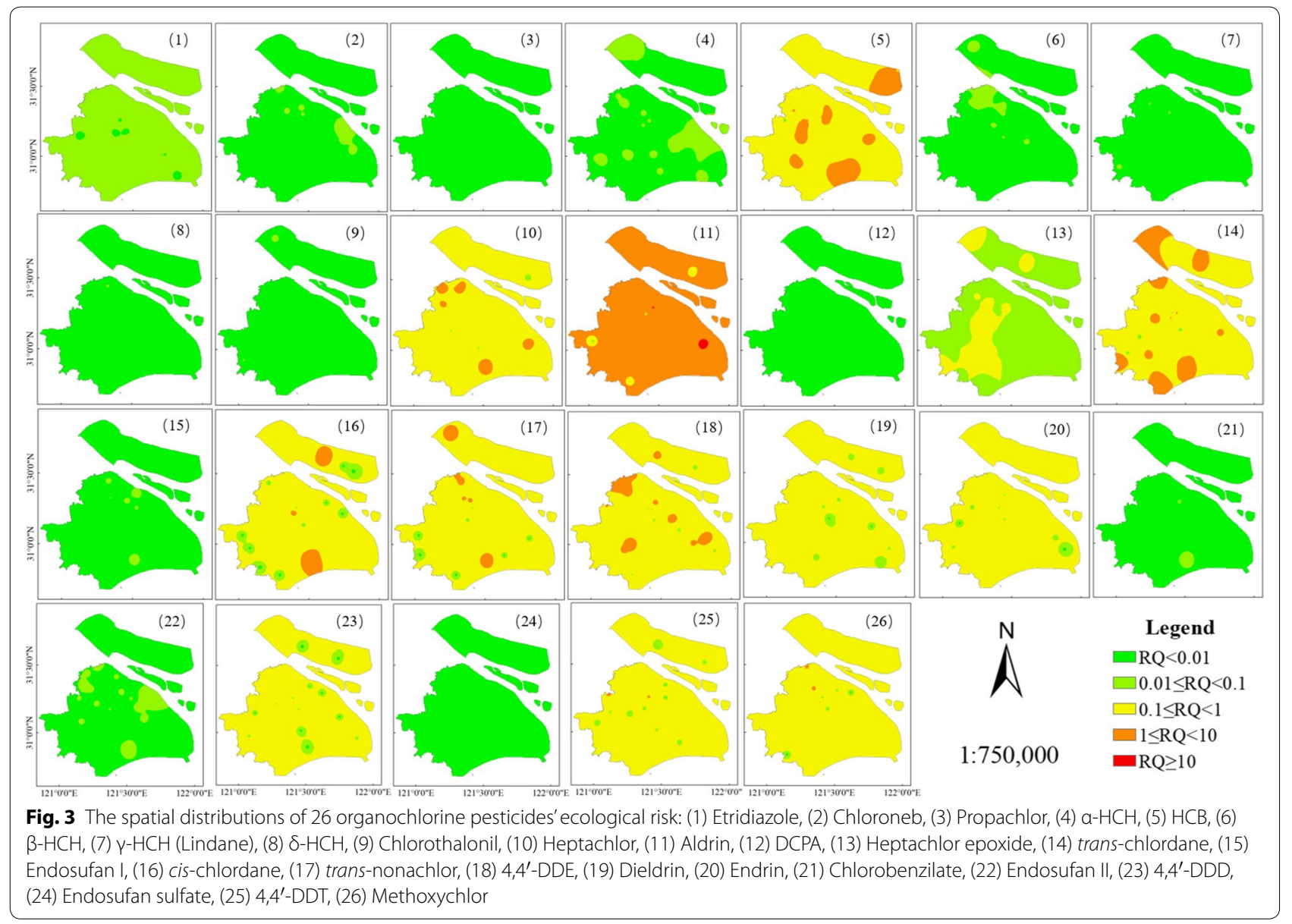

parts of Shanghai, some OCPs, such as heptachlor, transnonachlor, and 4,4'-DDE, formed triangle-shaped areas with higher local ecological risks, that were primarily concentrated in agricultural areas (Fig. 3). This result could possibly related to the continuous internal release from the sediment [6]. In contrast, there were significant differences in the ecological risks caused by diverse OCPs (Fig. 3). Nine OCPs, namely, HCB, heptachlor, aldrin, trans-chlordane, cis-chlordane, trans-nonachlor, 4,4'-DDE, 4,4'-DDT, and methoxychlor, were high risk to aquatic organisms in some areas (3.77\%-88.68\%) (Additional file 1: Table S10). Among them, aldrin had the highest ecological risk and was also the only OCP that reached the very high risk category at $3.77 \%$ in the region (Additional file 1: Table S10). This phenomenon was relevant to their high detected concentrations and high toxicity on aquatic organisms [4]. This means that their concentrations in some river waters had exceeded the predicted no-effect concentrations. Not only did this pose a threat to aquatic organisms, but also the consumption of aquatic organisms entailed a potential threat to human health due to the bioaccumulation of OCPs [8].

\section{Health risk assessment}

Figure 4 shows the cumulative probability distribution for the ILCR and hazard index (HI) in diverse population groups exposed to OCPs in the river waters of Shanghai. The median values of the ILCR for dermal contact were estimated to be between $7.564 \times 10^{-5}$ and $3.814 \times 10^{-4}$, and the median values of the ILCR for mistaken oral intake were from $6.078 \times 10^{-9}$ to $2.974 \times 10^{-8}$ (Fig. 4). From the median values, the ILCR for dermal contact in population groups was low risk $\left(1.0 \times 10^{-6}\right.$ $\left.1.0 \times 10^{-4}\right)$, except for male adults and female adults, whose ILCR were moderate risk $\left(1.0 \times 10^{-4}-1.0 \times 10^{-3}\right)$ (Fig. 4) [24]. The losses of life expectancy caused by dermal contact in diverse population groups were from 484.27 to $2440.41 \mathrm{~min}$ (Additional file 1: Fig. S4). The ILCR values caused by mistaken oral intake were very low risk $\left(<1.0 \times 10^{-6}\right)$ (Fig. 4), and the life-expectancy losses were between 0.04 and $0.19 \mathrm{~min}$ (Additional file 1: Fig. S4) [24]. The rankings of the ILCR for dermal contact according to age and gender were adults $>$ children $>$ seniors $>$ adolescents, and females $>$ males, while the rankings of ILCR caused by mistaken oral intake 

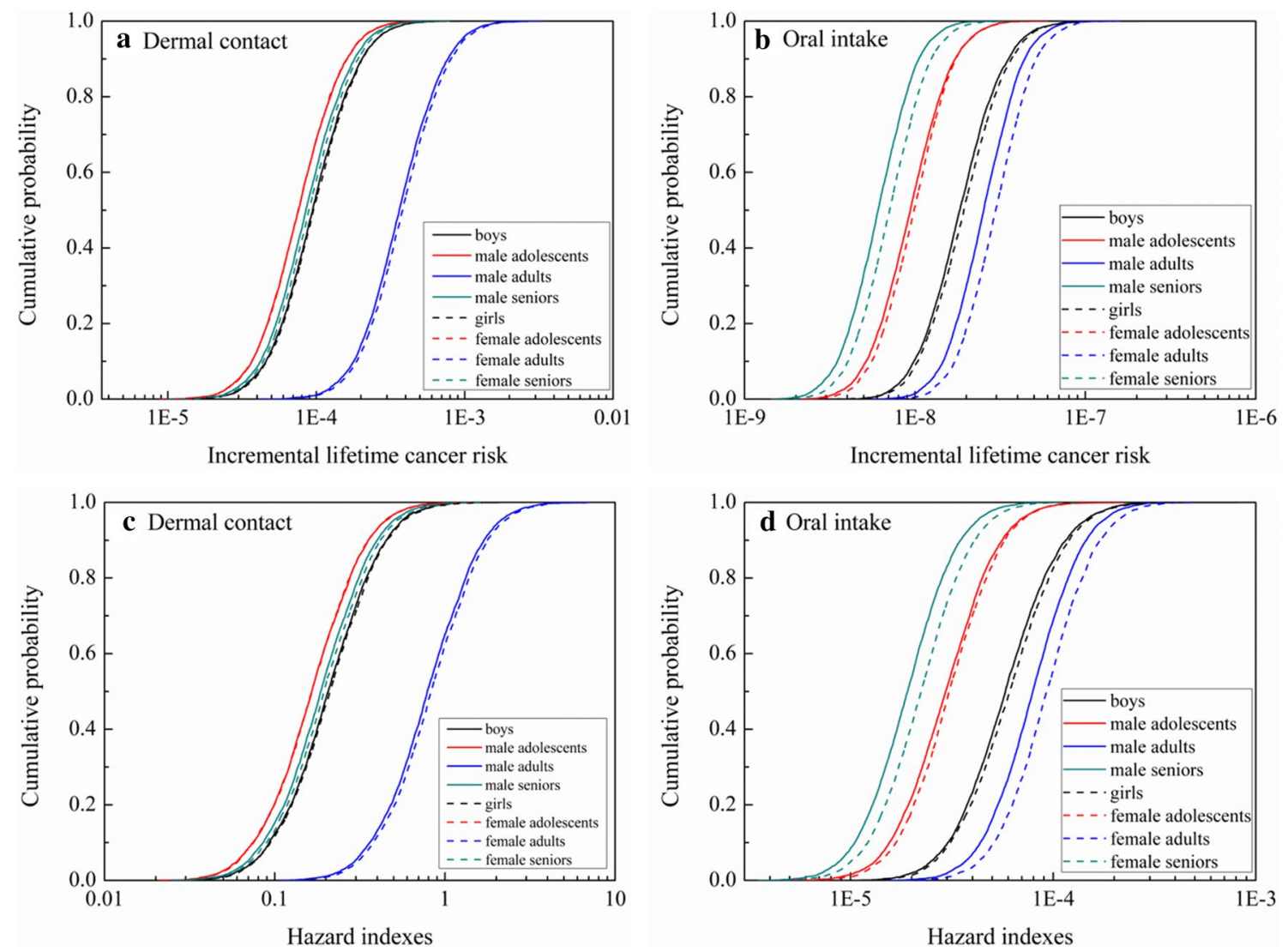

Fig. 4 Cumulative probability distribution chart of health risks for different population groups exposed to organochlorine pesticides from the river waters of Shanghai

were adults $>$ children $>$ adolescents $>$ seniors, and females $>$ males (Fig. 4). Adults had the highest ILCR in both exposure routes (Fig. 4), despite their largest body weight (Additional file 1: Table S6). It was because the exposure duration for adults would be much longer than that of the other three groups (Additional file 1: Table S6), which would make them have the highest exposure doses (Additional file 1: Fig. S4). The exposure duration of children was the shortest, but their intake rate was the largest. They also had the largest skin exposure ratio, and their low body weight accounted for their high exposure doses under both exposure routes (Additional file 1: Table S6, Fig. S4). This resulted in their higher ILCR values than those for both adolescents and seniors (Fig. 4). Children are sensitive to health risks, and more attention should be placed on this. According to gender, females in all the age groups showed higher cancer risks than males because females have lower body weights and this leads to higher exposure doses and ILCR values (Fig. 4, Additional file 1: Table S6, Fig. S4).

The median values of $\mathrm{HI}$ for diverse population groups caused by dermal contact were estimated to be from
$1.649 \times 10^{-1}$ to $8.294 \times 10^{-1}$, and the median values of $\mathrm{HI}$ caused by mistaken oral intake ranged from $1.912 \times 10^{-5}$ to $9.289 \times 10^{-5}$ (Fig. 4). From the median, the non-carcinogenic risks caused by dermal contact were much higher than that of mistaken oral intake, but the HI values of both exposure routes were smaller than 1 . This indicated that OCPs in the river waters of Shanghai did not cause significant non-carcinogenic health hazards (Fig. 4) [27]. The HI values of dermal contact at the 99.46th, 99.84th, 65.08th, 99.74th, 99.30th, 99.88th, 62.40th, and 99.68th percentiles for boys, male adolescents, male adults, male seniors, girls, female adolescents, female adults, and female seniors, respectively, were greater than 1. This indicated that the OCPs in Shanghai's river waters still caused a small number of people to be exposed to non-carcinogenic health hazards through dermal contact (Fig. 4) [27]. The HI values caused by mistaken oral intake indicated that people would not significantly be affected by OCPs in this manner (Fig. 4) [27].

With respect to different intensive land-use types, the ranking of the ILCR caused by dermal contact in decreasing order was as follows: inner city>island 
areas $>$ agricultural areas $>$ suburban towns $>$ industrial areas for all the population groups. For the HI values, the ranking was inner city $>$ island areas $>$ agricultural areas $>$ industrial areas $>$ suburban towns (Fig. 5). The ranking of the ILCR caused by mistaken oral intake in decreasing order was agricultural areas $>$ industrial areas $>$ suburban towns $>$ industrial areas $>$ inner city for all population groups. For HI values, the ranking was industrial areas $>$ agricultural areas $>$ inner city $>$ suburban towns $>$ island areas (Fig. 5). The rankings were variable between carcinogenic risk and non-carcinogenic risk or under diverse exposure routes, which was due to the diversified compositions of the OCPs in the rivers near different intensive land-use types. Each OCP has a unique $K_{\text {ow }}$ and molecular weight (Additional file 1: Table S7), which could lead to different dermal permeation constants. This results in different exposure doses and health risk rankings under diverse exposure routes (Fig. 5). Furthermore, the specific cancer slope factor and non-carcinogenic reference dose of each OCP could also affect the ILCR and HI values (Additional file 1: Table S7), making their rankings discrepant even for the same exposure route (Fig. 5). Therefore, to judge the health hazards of pollutants only using the concentrations of the compounds could produce inaccurate results.

According to the literature, the carcinogenic risk value of OCPs in this study, which was approximately $10^{-5}-10^{-4}$, was similar with that of surface waters and underground waters in the Shaying River [4], in edible fish from the East Lake of Wuhan [54], and in the surface waters of the Three Gorges Reservoir and the Huaihe River in China [7, 55] (Additional file 1: Table S11). In this study, the OCPs in the river waters of the Shanghai river network had higher carcinogenic risks for humans than those in the drinking water sources of South China [38], the tap water of Jiangsu [56], and the drinking water of Aba Prefecture, Sichuan [35], whose carcinogenic risk values were between $10^{-10}$ and $10^{-6}$ (Additional file 1: Table S11). In the river waters of the Yeongsan and Seomjin River basins of Korea, there were higher carcinogenic risks of $10^{-5}$ and $10^{-2}$ associated with OCPs [57] (Additional file 1: Table S11). As far as the non-carcinogenic
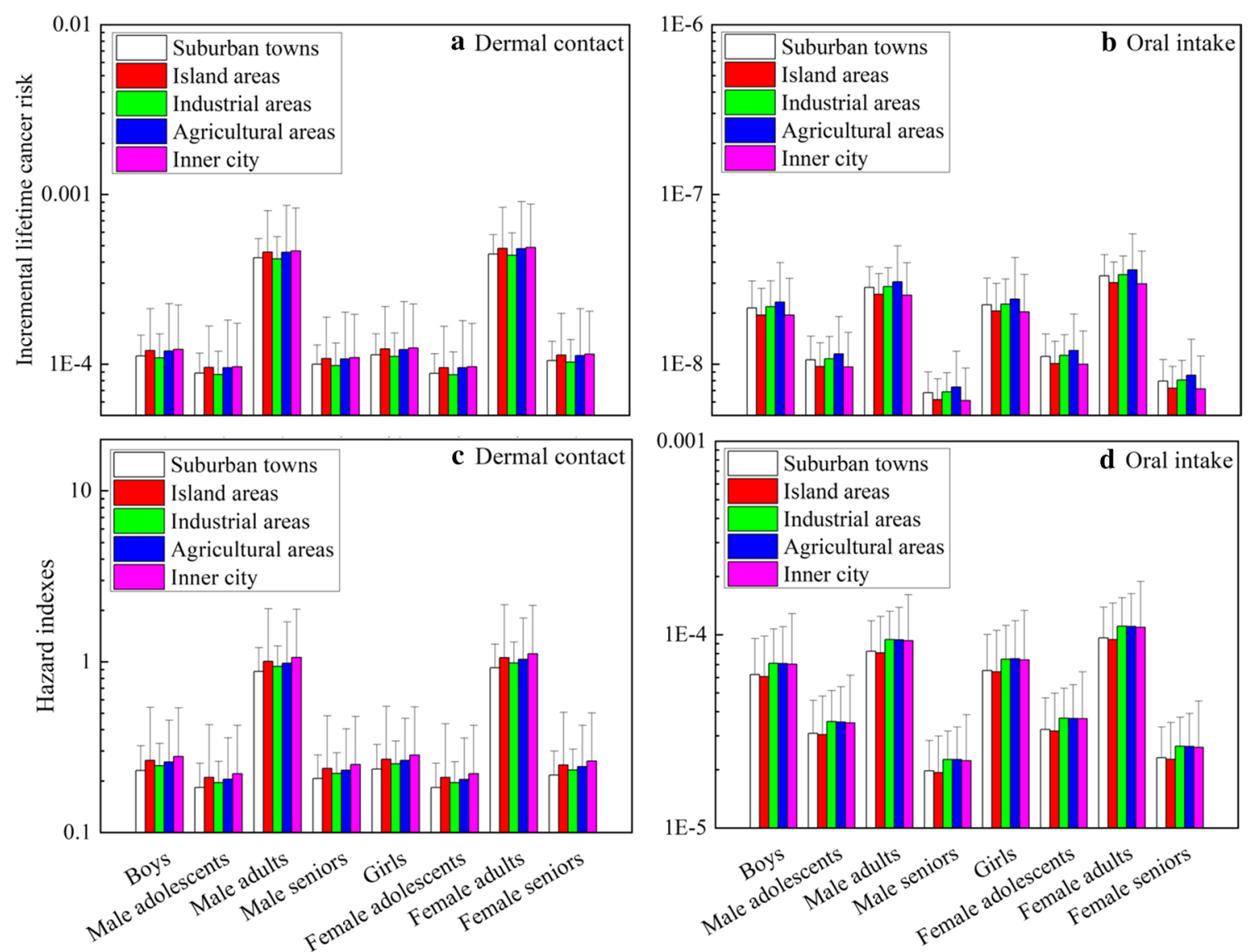

Fig. 5 Health risks in population groups from different intensive land-use types exposed to organochlorine pesticides in the river waters of Shanghai 
risk, the current finding was also strengthened by previously published data from around the world (Additional file 1: Table S11). The results found in this study were similar to that of edible fish from the East Lake of Wuhan, with estimated non-carcinogenic risk value of $10^{-1}$ [54], slightly higher than the underground rivers of Chongqing in China [39], the tap water from the Ebro River in Spain [40], and the surface waters of Lake Chaohu in China [58] and the River Ravi in Pakistan [59], with non-carcinogenic risk values ranging from $10^{-5}$ to $10^{-2}$ (Additional file 1: Table S11). In general, the non-carcinogenic risks above were all within the negligible risk level.

\section{Conclusions}

The concentrations of 26 OCPs in the urbanized river network of Shanghai were determined. Six OCPs, namely, chloroneb, chlorobenzilate, chlorothalonil, propachlor, heptachlor, and heptachlor epoxide, require more attention due to their high concentrations and high detection frequencies. On the whole, the concentrations of OCPs in the northern and southern regions of Shanghai were significantly higher than that in other regions, and the OCP concentrations in the SPM were higher than that in the surface water. The fluctuation of the OCP concentrations among diverse intensive land-use types was not significant $(p>0.05)$, but the OCP concentrations in the river waters of the inner city varied most significant. The $K_{\mathrm{p}}$ values of the $\sum_{26}$ OCPs were negatively correlated with the TSS contents $(p<0.01)$. Some OCPs formed triangleshaped areas with higher local ecological risks, which were concentrated in agricultural areas, and there were nine OCPs of high risk in some areas. The health risk assessment results showed the ILCR for dermal contact and mistaken oral intake were generally low, except for adults, whose ILCR caused by dermal contact were moderate risk. The carcinogenic and non-carcinogenic risks caused by dermal contact were much higher than that of mistaken oral intake, but the HI values of both exposure routes were less than one, indicating that the OCPs in the river waters did not pose significant non-carcinogenic health hazards for most people.

\section{Supplementary information}

Supplementary information accompanies this paper at https://doi. org/10.1186/s12302-020-00322-9.

Additional file 1. Additional figures and tables.

\section{Abbreviations}

OCPs: Organochlorine pesticides; ILCR: Incremental lifetime cancer risk; HI: Hazard index; GPS: Global Positioning System; USEPA: United States Environmental Protection Agency; SS: Sampling sites; GFF: Glass microfiber filters; SPE: Solid phase extraction; DCM: Dichloromethane; SPM: Suspended particulate matter; TSS: Total suspended solids; GC-MS: Gas chromatography-mass spectrophotometry; HPLC: High-performance liquid chromatography; PAHs: Polycyclic aromatic hydrocarbons; LOD: Limits of detection; S/N: Signal-tonoise ratio; LOQ: Limits of quantification; DCPA: Dacthal; IDW: Inverse distance weight; RQ: Risk quotient; PNEC: The predicted no-effect concentration; SSD: Species sensitivity distribution; $\mathrm{LC}_{50}$ : Median lethal concentration; $\mathrm{EC}_{50}$ : Median effective concentration; NOEC: No observed effect concentration; LOEC: Lowest observed effect concentration; SD: Standard deviation; $K_{\mathrm{p}}$ : Partition coefficient.

\section{Acknowledgements}

Not applicable.

\section{Authors' contributions}

CC and LM designed the study. CC and WZ were involved in the sampling, experiments, data analysis, and manuscript writing. LM, SC, and KZ contributed to correction of the manuscript. All authors read and approved the final manuscript.

\section{Funding}

This work was financially supported by Most Key Program of China

(2017ZX07206-003, 2017YFC0505705) and the Natural Science Foundation of China (No. 21377098).

\section{Availability of data and materials}

The datasets used and analyzed during the current study are available from the corresponding author on reasonable request.

Ethics approval and consent to participate

Not applicable.

\section{Consent for publication}

Not applicable.

\section{Competing interests}

The authors declare that they have no competing interests.

\section{Author details}

${ }^{1}$ State Key Laboratory of Pollution Control and Resources Reuse, College of Environmental Science and Engineering, Tongji University, 1239 Siping Road, Shanghai 200092, People's Republic of China. ${ }^{2}$ Shanghai Key Laboratory of Special Artificial Microstructure Materials and Technology, School of Physics Science and Engineering, Tongji University, Shanghai 200092, People's Republic of China.

Received: 4 December 2019 Accepted: 2 March 2020

Published online: 11 March 2020

\section{References}

1. Grung M, Lin Y, Zhang H et al (2015) Pesticide levels and environmental risk in aquatic environments in China-a review. Environ Int 81:87-97

2. Dietz R, Riget F, Sonne C et al (2004) Seasonal and temporal trends in polychlorinated biphenyls and organochlorine pesticides in East Greenland polar bears (Ursus maritimus), 1990-2001. Sci Total Environ 331(1-3):107-124

3. Wang T, Lu Y, Zhang H et al (2005) Contamination of persistent organic pollutants (POPs) and relevant management in China. Environ Int 31(6):813-821

4. Bai Y, Ruan X, Hoek JPVD (2018) Residues of organochlorine pesticides (OCPs) in aquatic environment and risk assessment along Shaying River, China. Environ Geochem Health 40(6):2525-2538

5. Li J, Li F, Liu Q (2015) Sources, concentrations and risk factors of organochlorine pesticides in soil, water and sediment in the Yellow River estuary. Mar Pollut Bull 100(1):516-522

6. Wang W, Bai J, Xi M et al (2017) Occurrence, sources, and risk assessment of OCPs in surface sediments from urban, rural, and reclamationaffected rivers of the Pearl River Delta, China. Environ Sci Pollut Res Int. 24(3):2535-2548 
7. Yang Y, Liu M, Yun X et al (2017) Profiles and risk assessment of organochlorine pesticides in Three Gorges Reservoir, China. Clean Soil Air Water 45(2):1600823-1600829

8. Wang Y, Zhang S, Cui W et al (2018) Polycyclic aromatic hydrocarbons and organochlorine pesticides in surface water from the Yongding River basin, China: seasonal distribution, source apportionment, and potentia risk assessment. Sci Total Environ 618:419-429

9. Bakke T, Källqvist T, Ruus A et al (2010) Development of sediment quality criteria in Norway. J Soils Sediments 10(2):172-178

10. United States Environmental Protection Agency (USEPA) (2015) National recommended water quality criteria. USEPA, Washington, DC

11. State Environmental Protection Administration of China (SEPA) (2002) Environmental Quality Standard for Surface Water (GB 3838-2002). China Environmental Science Press, Beijing

12. FAO/WHO (2001) Pesticide Residues in Food-2000. Evaluations-2000. Part II - toxicology. World Health Organization, Joint FAO/WHO Meeting on Pesticide Residues, Geneva

13. Bao LJ, Maruya KA, Snyder SA et al (2012) China's water pollution by persistent organic pollutants. Environ Pollut 163:100-108

14. Harmouche-Karaki M, Matta J, Helou Ket al (2018) Serum concentrations of selected organochlorine pesticides in a Lebanese population and their associations to sociodemographic, anthropometric and dietary factors: ENASB study. Environ Sci Pollut Res 25(15):14350-14360

15. Shanghai Municipal Statistics Bureau (SMSB) (2018) Shanghai Statistical Year Book. China Statistics Press, Beijing

16. Shanghai Municipal People's Government (SMPG) (2010) The Encyclopedia of Shanghai. Shanghai Science and Technology Press, Shanghai

17. Bi C, Wang X, Jia J et al (2018) Spatial variation and sources of polycyclic aromatic hydrocarbons influenced by intensive land use in an urbanized river network of East China. Sci Total Environ 627:671-680

18. Liu S, Liu X, Liu M et al (2016) Levels, sources and risk assessment of PAHs in multi-phases from urbanized river network system in Shanghai. Environ Pollut 219:555-567

19. United States Environmental Protection Agency (USEPA) (2012) Determination of semivolatile organic chemicals in drinking water by solid phase extraction and capillary column gas chromatography/mass spectrometry (GC/MS). USEPA, Washington, DC

20. World Health Organization (WHO) (2001) Water quality: quidelines, standards and health. International Water Association, London

21. Liang X, Zhou J, Li J et al (2015) Appication of Species Sensitivity Distribution (SSD) to derivation of water quality criteria for pesticides. J Ecol Rural Environ. 31(3):398-405

22. Wang D, Wang Y, Singh VP et al (2018) Ecological and health risk assessment of PAHs, OCPs, and PCBs in Taihu Lake basin. Ecol Indic. 92:171-180

23. Peng $X$, Ou W, Wang C et al (2014) Occurrence and ecological potential of pharmaceuticals and personal care products in groundwater and reservoirs in the vicinity of municipal landfills in China. Sci Total Environ 490:889-898

24. Qu C, Qi S, Yang D et al (2015) Risk assessment and influence factors of organochlorine pesticides (OCPs) in agricultural soils of the hill region: a case study from Ningde, southeast China. J Geochem Explor 149:43-51

25. Wang XP, Han JC, Bi CJ et al (2017) Distribution, sources, and risk assessment of polychlorinated biphenyls in surface waters and sediments of rivers in Shanghai, China. Front. Earth Sci. 11(2):283-296

26. Chen C, Xia Z, Wu M et al (2017) Concentrations, source identification, and lung cancer risk associated with springtime PM25-bound polycyclic aromatic hydrocarbons (PAHs) in Nanjing, China. Arch Environ Contam Toxicol 73(3):391-400

27. The Risk Assessment Information System (RAIS) (2019) The risk assessment information system. https://rais.ornl.gov/index.htm

28. United States Environmental Protection Agency (USEPA) (2004) Risk Assessment Guidance for Superfund Volume I: Human Health Evaluation Manual (Part E, Supplemental Guidance for Dermal Risk Assessment) Final. Washington, DC: USEPA

29. Yang Y, Huu J, Tao S (2005) Loss of life expectancy analysis for cancer risk in Tianjin area. Environ. Sci. 26(1):168-172

30. National Health Commission of the People's Republic of China (NHCC) (2018) China Health Statistics Yearbook. Peking Union Medical College Press, Beijing
31. Sun Z, Zhu Y, Zhuo S et al (2017) Occurrence of nitro- and oxy-PAHs in agricultural soils in eastern China and excess lifetime cancer risks from human exposure through soil ingestion. Environ Int 108:261-270

32. Li J, Huang Y, Ye R et al (2015) Source identification and health risk assessment of Persistent Organic Pollutants (POPs) in the topsoils of typical petrochemical industrial area in Beijing, China. J Geochem Explor. 158:177-185

33. United States Environmental Protection Agency (USEPA) (1989) Risk assessment guidance for Superfund, Volume I, human health evaluation manual (Part A). Washington, DC: USEPA

34. Fytianos K, Meesters RJW, Schröder HFR et al (2006) Distribution of organochlorine pesticides in surface water and sediments in Lake Volvi (northern Greece). Int J Environ Anal Chem 86(1-2):109-118

35. Liu H, Hu Y, Qi S et al (2014) Organochlorine pesticide residues in surface water from Sichuan Basin to Aba Prefecture profile, east of the Tibetan Plateau. Front Earth Sci. 9(2):248-258

36. Chakraborty P, Khuman SN, Selvaraj S et al (2016) Polychlorinated biphenyls and organochlorine pesticides in River Brahmaputra from the outer Himalayan Range and River Hooghly emptying into the Bay of Bengal: occurrence, sources and ecotoxicological risk assessment. Environ Pollut 219:998-1006

37. Ali U, Bajwa A, Chaudhry MJl et al (2016) Significance of black carbon in the sediment-water partitioning of organochlorine pesticides (OCPs) in the Indus River, Pakistan. Ecotoxicol Environ Saf. 126:177-185

38. Wei L, Yang Y, Li QX et al (2014) Composition, distribution, and risk assessment of organochlorine pesticides in drinking water sources in South China. Water Qual Exposure Health 7(1):89-97

39. Hu Y, Qi S, Zhang J et al (2011) Assessment of organochlorine pesticides contamination in underground rivers in Chongqing, Southwest China. J Geochem Explor. 111(1-2):47-55

40. Ferre-Huguet N, Bosch C, Lourencetti C et al (2009) Human health risk assessment of environmental exposure to organochlorine compounds in the Catalan stretch of the Ebro River, Spain. Bull Environ Contam Toxicol. 83(5):662-667

41. Aydin ME, Ozcan S, Beduk F et al (2013) Levels of organochlorine pesticides and heavy metals in surface waters of Konya closed basin, Turkey. Sci. World J. 2013:849716

42. Malik A, Ojha P, Singh KP (2009) Levels and distribution of persistent organochlorine pesticide residues in water and sediments of Gomti River (India) — a tributary of the Ganges River. Environ Monit Assess 148(1-4):421-435

43. Castilho JAA, Fenzl N, Guillen SM et al (2000) Organochlorine and organophosphorus pesticide residues in the Atoya river basin, Chinandega, Nicaragua. Environ Pollut. 110(3):523-533

44. Leong KH, Tan LL, Mustafa AM (2007) Contamination levels of selected organochlorine and organophosphate pesticides in the Selangor River, Malaysia between 2002 and 2003. Chemosphere 66(6):1153-1159

45. Zhang Z, Huang J, Yu G et al (2004) Occurrence of PAHs, PCBs and organochlorine pesticides in the Tonghui River of Beijing, China. Environ Pollut. 130(2):249-261

46. Zhen L, Li F, Huang H et al (2011) Households' willingness to reduce pollution threats in the Poyang Lake region, southern China. J Geochem Explor 110(1):15-22

47. Cui C, Han Q, Jiang L et al (2018) Occurrence, distribution, and seasonal variation of antibiotics in an artificial water source reservoir in the Yangtze River delta, East China. Environ Sci Pollut Res Int 25(20):19393-19402

48. Udensi JU, Ogbulie TE, ljeoma EN et al (2017) Study on the effects of hydraulic dredging and disposal operations on water quality of Nworie River, South-Eastern Nigeria. Int J Environ Monit Anal. 5(2):25-31

49. Kangabam RD, Selvaraj M, Govindaraju M (2018) Spatio-temporal analysis of floating islands and their behavioral changes in Loktak Lake with respect to biodiversity using remote sensing and GIS techniques. Environ Monit Assess 190(3):118-131

50. Yin Z, Yu N, Wang Y et al (2018) Oxygen transfer numerical investigation using intermittent aeration technology under regular waves. Water Air Soil Pollut 229(5):164-174

51. Elfman L, Tooke NE, Patring JDM (2011) Detection of pesticides used in rice cultivation in streams on the island of Leyte in the Philippines. Agric Water Manage 101(1):81-87 
52. Qin N, He W, Kong XZ et al (2014) Distribution, partitioning and sources of polycyclic aromatic hydrocarbons in the water-SPM-sediment system of Lake Chaohu, China. Sci Total Environ 496:414-423

53. Luo XJ, Mai BX, Yang QS et al (2008) Distribution and partition of polycyclic aromatic hydrocarbon in surface water of the Pearl River Estuary, South China. Environ Monit Assess. 145(1-3):427-436

54. Cui L, Ge J, Zhu Y et al (2015) Concentrations, bioaccumulation, and human health risk assessment of organochlorine pesticides and heavy metals in edible fish from Wuhan, China. Environ Sci Pollut Res Int 22(20):15866-15879

55. Wang B, Yu G, Yu YJ et al (2009) Health risk assessment of organic pollutants in Jiangsu reach of the Huaihe River, China. Water Sci Technol. 59(5):907-916

56. Li B, Qu C, Bi J (2012) Identification of trace organic pollutants in drinking water and the associated human health risks in Jiangsu Province, China. Bull Environ Contam Toxicol. 88(6):880-884
57. Lee SH, Ra JS, Choi JW et al (2014) Human health risks associated with dietary exposure to persistent organic pollutants (POPs) in river water in Korea. Sci Total Environ 470-471:1362-1369

58. He W, Qin N, He Q-S et al (2012) Characterization, ecological and health risks of DDTs and $\mathrm{HCH}$ in water from a large shallow Chinese lake. Ecol Inform. 12:77-84

59. Baqar M, Sadef Y, Ahmad SR et al (2018) Organochlorine pesticides across the tributaries of River Ravi, Pakistan: human health risk assessment through dermal exposure, ecological risks, source fingerprints and spatiotemporal distribution. Sci Total Environ 618:291-305

\section{Publisher's Note}

Springer Nature remains neutral with regard to jurisdictional claims in published maps and institutional affiliations.

\section{Submit your manuscript to a SpringerOpen ${ }^{\circ}$ journal and benefit from:}

- Convenient online submission

- Rigorous peer review

- Open access: articles freely available online

- High visibility within the field

- Retaining the copyright to your article

Submit your next manuscript at $\boldsymbol{\nabla}$ springeropen.com 